\title{
Heavy Metal: a misused term?
}

\section{Olivier Pourret ${ }^{1, *}$, Jean-Claude Bollinger ${ }^{2}$, Andrew Hursthouse $^{3}$}

1 UniLaSalle, 60000 Beauvais, France

2 Université de Limoges, PEREINE, Faculté des Sciences et Techniques, 87060 Limoges, France

3 School of Computing, Engineering \& Physical Sciences, University of the West of Scotland, Paisley, PA1 2BE, UK

*Correspondence: olivier.pourret@unilasalle.fr

Abstract: The use of the term "heavy metal" is regularly questioned by the scientific community. Here, we followed the evolution (1970-2020) in the number of published papers including this term in their title. Thus, we can evidence a continuous, albeit sometimes stabilizing, increase especially in environmental journals. After several other warning opinions, we propose that it should be replaced in the scientific literature by terms like "metal", "metalloid", "trace metal elements" or "potentially toxic element".

Keywords: Heavy metals; trace metal elements; metal; metalloid; potentially toxic elements 


\section{History}

The chemical elements are now well characterized, and their classification in the socalled "Periodic System" reached its 150-year celebration in 2019 [1]. They are also allocated to various series, according to similarities in their properties or their electronic structure; among them are the so-called "heavy metals". Initially, the term "heavy metal" was based on categorization by density or molar mass (zinc or copper have relatively low density and molar mass compared to lanthanides and actinides). It is often used as a group name for metals and metalloids (i.e., arsenic) that are associated with contamination and potential toxicity in the environment. The "heavy metals" list is not clearly defined and often mixes metals and metalloids. Ultimately, the pejorative connotation of "heavy" associated with the toxicity of metal induces a kind of fear in society. From a quick perusal of the recent scientific literature, it appears that the (mis)use of the term "heavy metal(s)" seems still to be rampant: therefore we decided to follow it, as described in the present article.

In elementary science classes, one often asks to the children: "Which weighs more-a pound of lead or a pound of feathers?" The seemingly naive answer to the familiar riddle is the pound of lead. The correct answer, of course, is that they weigh the same amount[2]. Unfortunately, our own experience has demonstrated that this confusion remains for a part of college students! Apart this funny side, it seems that it is not as easy to understand what really a "heavy metal" is, and its original definition thus pertains, although several "heavy" metallic elements have somewhat low density.

In 1980, Nieboer and Richardson[3] had already proposed the replacement of this nondescript term by biologically and chemically significant classification. Moreover, according to the International Union of Pure and Applied Chemistry (IUPAC) [4], the term "heavy metal" is considered imprecise at best, and meaningless and misleading at worst. The use of this term is strongly discouraged, especially as there is no standardized 
definition of this term. In 2004, Hodson[5] considered it as geochemical Bogeyman; In 2007, Chapman[6] first proposed to keep this term for music not for science. In 2010, Hübner et al.[7] proposed to move on from semantics to pragmatics, whereas Madrid[8] recalled the long-standing and sometimes forgotten controversy. Nikinmaa and Schlenk[9] further insisted on the ill-defined term. In 2011, Bhat and Khan[10] defined them as an ambiguous category of inorganic contaminants, nutrients and toxins. In 2012, Chapman[11] continued to wrote on "the cacophony not the symphony" around "heavy metals" and Batley et al.[12] further detailed on the usefulness of this term.

However, some authors still proposed their classification; in 2010 Appenroth[13] defined "heavy metals" in Plant Sciences, and Ali and Kahn[14] proposed their own "comprehensive" definition (Figure 1). In some classical textbooks, their authors continue to use the term in their title[15-16]; however, they now discuss the misuse of the term. Some other authors have clearly changed their mind and revised the content of their textbook[17].
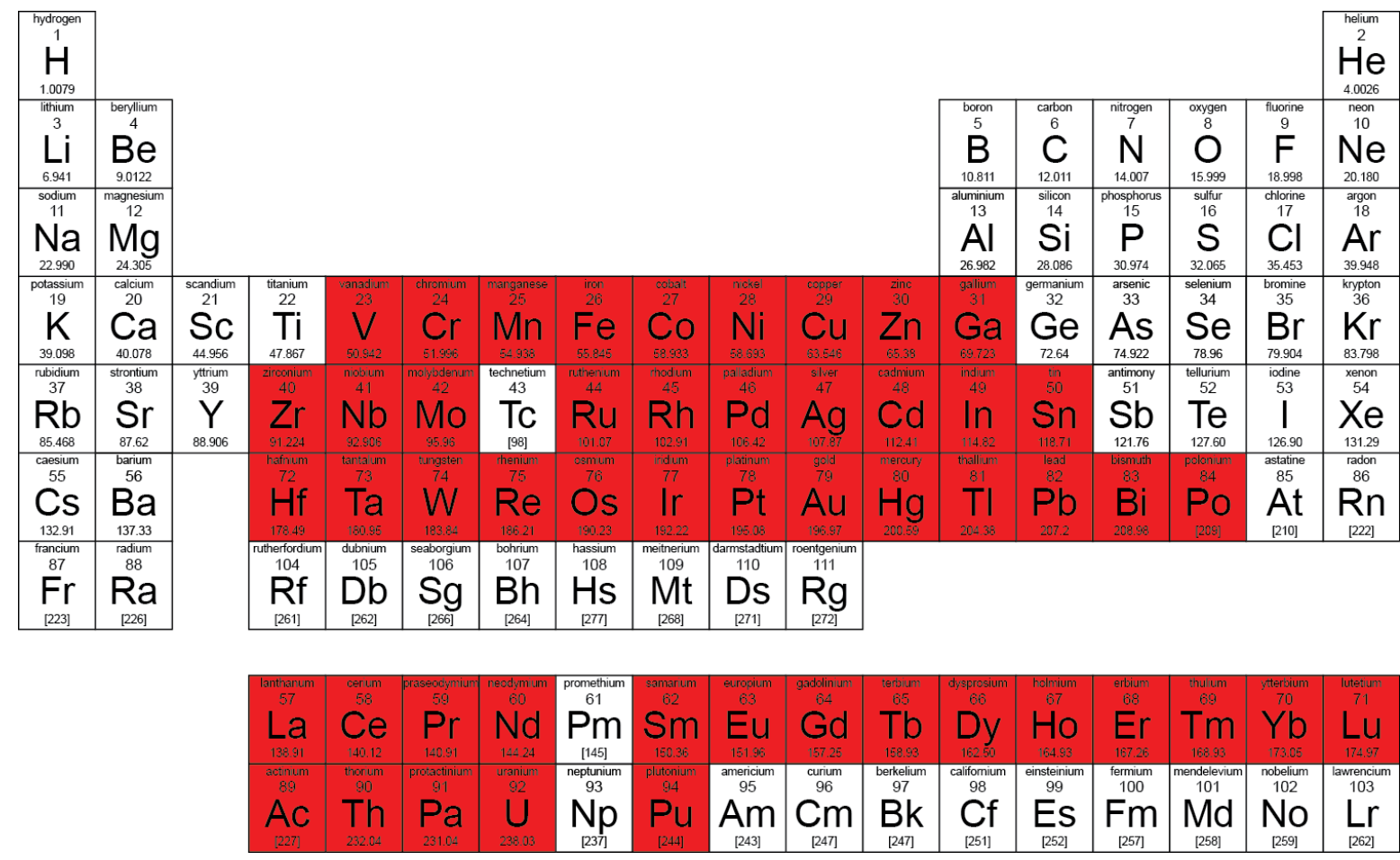

Figure 1 Periodic table highlighting "heavy metals", redrawn from Ali and Kahn [11]. 
In 2018, Pourret and Bollinger [18] further questioned on the use of the term "heavy metals" : to use or not to use? and Pourret [19] proposed to ban this term from the scientific literature. Eventually, Pourret and Hursthouse[20] and Pourret et al.[21] proposed to replace the term with "potentially toxic elements". Indeed, due to their persistence and indestructible nature (only changes in their chemical species can occur), most of them are unfortunately able to definitively pollute groundwater [22] or soils [23].

All so-called "heavy metals" and their compounds may have relatively high toxicity: human exposure to lead by the addition of tetraethyl-lead to gasoline as an antiknock agent, or to lead paint is well documented, however lead-acid battery does not pose direct threat to humans although its disposal may generate environmentally hazardous waste.

Nonetheless, metals are not always toxic, and some are in fact essential: depending on the dosage and exposure levels and the receiving organism/population, it may be essential or toxic. Known for its use in the US five-cent coin (thus its nickname), nickel is one of the most versatile metals found on Earth: nickel is essential for life (functional in some proteins) and its deficiency is accompanied by histological and biochemical changes and reduced iron resorption and may lead to anemia[24]. Physical organic chemists refer the isotope effects of any elements other than $\mathrm{H}$ as "heavy isotope effects". 


\section{Current status}

The term is increasingly used in the scientific literature (Figure 2), especially in articles pertaining to multidisciplinary environmental issues (see Figure 3 for the year 2019). Despite the repeated calls to stop using the term (including ours), and the apparent regular publication of the articles related to this controversy (Table 1), the use of the term "heavy metal" appears not to have declined in the scientific literature (Figure 2a). Indeed, the use of the term is increasing rather than declining. It should be noted that even if the total number of publications has also simultaneously increased: the proportion of publications using this term have globally increased from $0.074 \%$ in 2000 to $0.163 \%$ in 2020 (Figure $2 b)$.

(a)

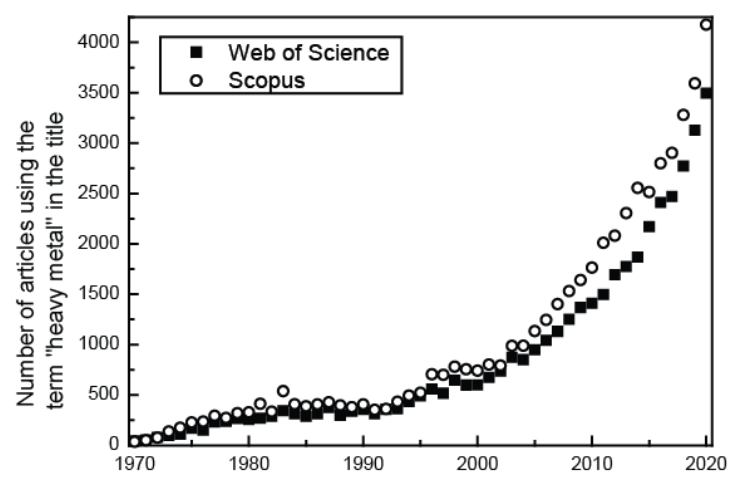

(b)

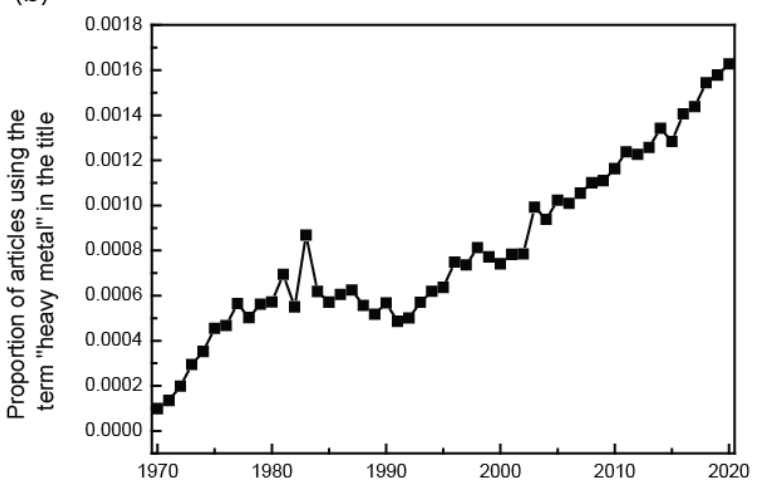

Figure 2 (a) Evolution of the number of publications using the term "heavy metal*" in the title (sourced from Scopus and the Web of Science using the term "heavy

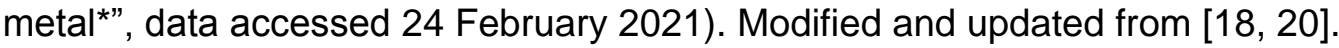
(b) Evolution of publications (number of articles using the term divided by the total number of all articles published that year) using the term "heavy metal" in the title (data from Scopus using "heavy metal*"search, accessed on 24 February 2021). 
The term "heavy metal" is a common term used for decades in the sciences, and even more in environmental sciences (Figure 3), particularly in studies of pollution impacts [20]. If we focus on Top journals from the Environmental Science category (selection from Pourret and Bollinger[18]), we can notice a "plateau" or even a small decrease (Figure 4).

Table 1 Type of article and number of citations of papers related to the controversy use of the term "heavy metal" (updated from Pourret and Bollinger [13]; data accessed on 24 February 2021).

\begin{tabular}{|c|c|c|c|}
\hline \multirow[t]{2}{*}{ Reference } & \multirow[t]{2}{*}{ Type of article } & \multicolumn{2}{|c|}{ Number of citations } \\
\hline & & Scopus & $\begin{array}{l}\text { Web of } \\
\text { Science }\end{array}$ \\
\hline Nieboer and Richardson (1980)[3] & Full paper & 864 & 841 \\
\hline Duffus (2002)[4] & Full paper & 617 & 565 \\
\hline Hodson (2004)[5] & Invited paper & 49 & 40 \\
\hline Chapman (2007)[6] & Letter & 9 & 6 \\
\hline Hübner et al. (2010)[7] & Perspective paper & 28 & 23 \\
\hline Madrid (2010)[8] & Letter & 16 & 15 \\
\hline Appenroth (2010)[13] & Review & 45 & 41 \\
\hline Nikinmaa and Schlenk (2010)[9] & Editorial & 5 & 5 \\
\hline Chapman (2012)[11] & Letter & 9 & 9 \\
\hline Batley (2012)[12] & Letter & 9 & 9 \\
\hline Pourret and Bollinger (2018)[18] & Letter & 25 & 24 \\
\hline Pourret (2018)[19] & Letter & 13 & 11 \\
\hline Ali and Kahn (2018)[14] & Full paper & 44 & 35 \\
\hline Pourret and Hursthouse (2019)[20] & Letter & 16 & 13 \\
\hline
\end{tabular}




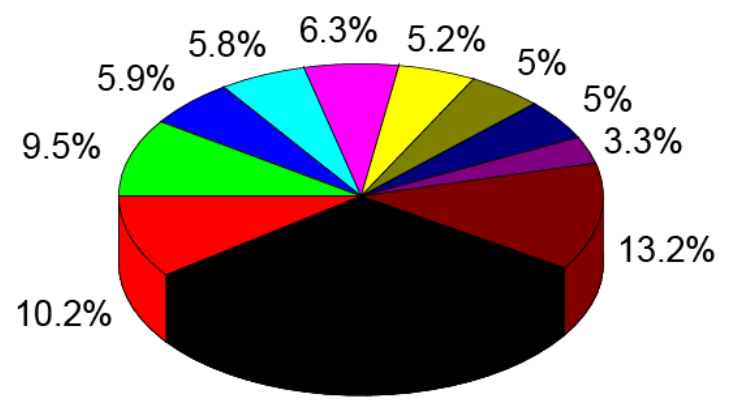

$30.7 \%$

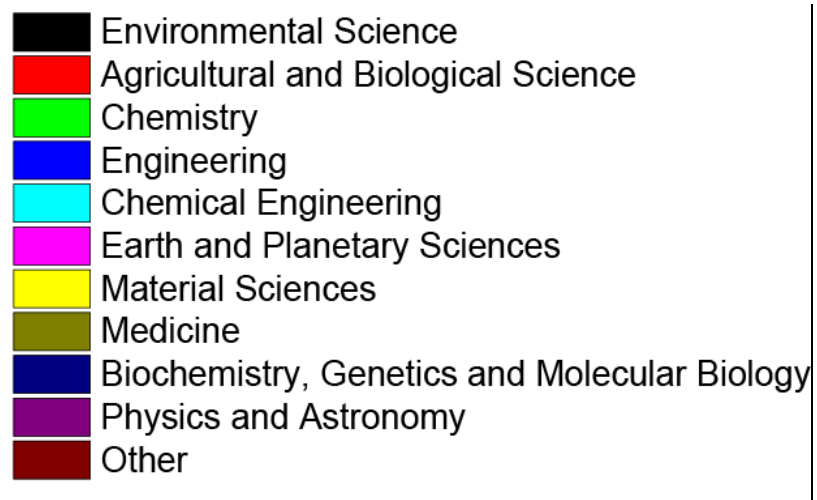

Figure 3 Proportion of publication by research areas in 2020 using the term "heavy metal*" in the title (sourced from Scopus using the term "heavy metal", data accessed on 24 February 2021). Modified and updated from [20].

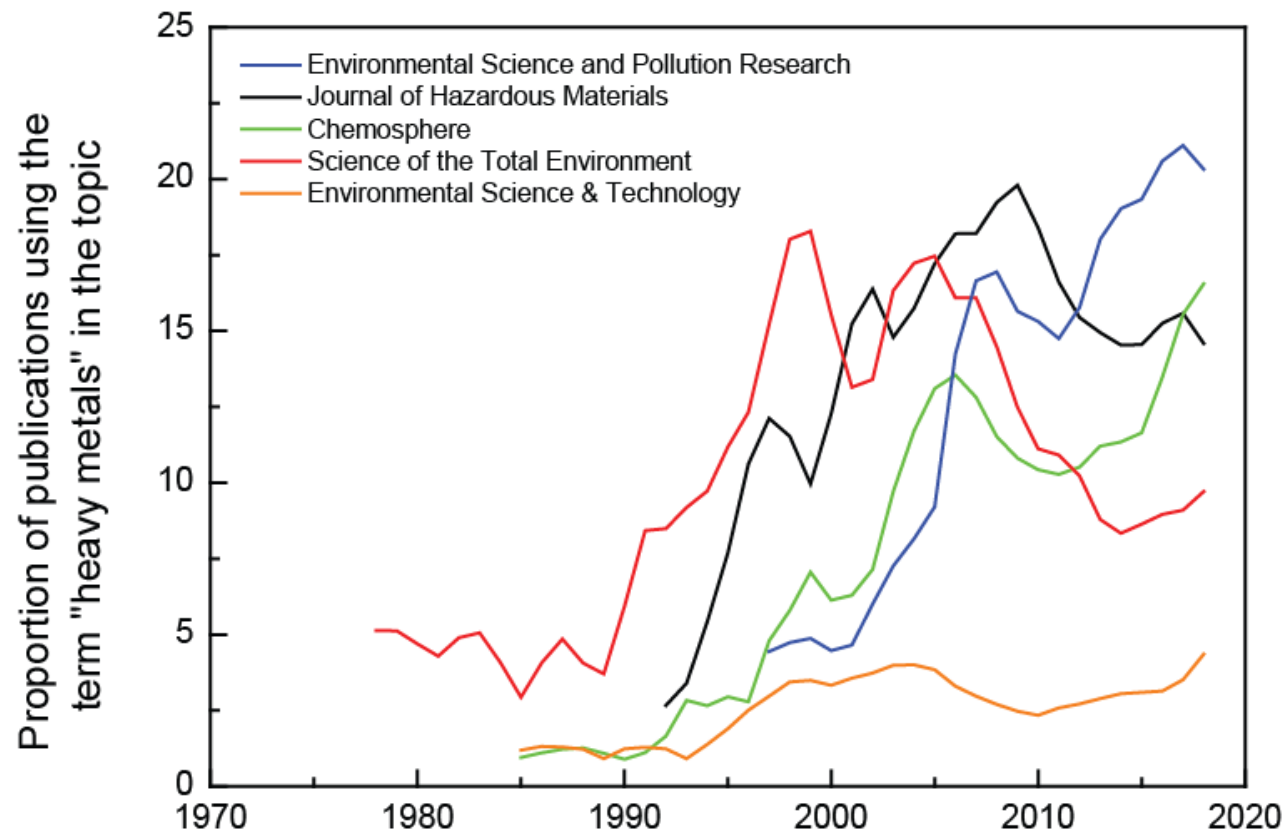

Figure 4 Evolution of publications (number of articles using the term divided by the total number of all articles published that year) using the term "heavy metal" in the topic for journals that highly used "heavy metal" term (data from Web of Science using "heavy metal"search, plotted using a 3 year span moving average, accessed on 24 February 2021). 
Indeed, if we look into this with more detail, and choose four journals, like Pourret and Bollinger[18] did, in which the term "heavy metal" is frequently used (i.e., Journal of Hazardous Materials, Chemosphere, Science of the Total Environment, and Environmental Science and Pollution Research), we notice an exponential increase during the last 30 years, related to the increasing number of articles; however, the proportion of articles using the term "heavy metal" remains stable at around 3\% for Environmental Science \& Technology (selected as a reference), whereas the use of the term has stabilized in Science of the Total Environment and Chemosphere (between 10\% and 15\%), and the Journal of Hazardous Materials or Environmental Science and Pollution Research still see high levels of use of this term (up to $20 \%$ ) (Figure 4). If we further look at the number of articles published in 2019 with the term "heavy metal" in their title (Table 2), Environmental Science and Pollution Research published the higher number of articles with "heavy metal" in their title (102) and up to $7 \%$ of article published in Environmental Monitoring and Assessment used this term. In Acta Geochimica, 5\% of published article (3/67) used the term "heavy metal" in their title.

Table 2 Number of publications during 2019 using the term "heavy metal" in the title for the ten most common sources and proportion of articles (from Scopus using "heavy metal*" search, data accessed on 24 February 2021).

\begin{tabular}{lcc}
\hline Journal title & $\begin{array}{c}\text { Number of } \\
\text { articles }\end{array}$ & Proportion \\
\hline Environmental Science And Pollution Research & 102 & $3 \%$ \\
Science Of The Total Environment & 95 & $2 \%$ \\
Ecotoxicology And Environmental Safety & 58 & $4 \%$ \\
Environmental Monitoring And Assessment & 55 & $7 \%$ \\
Chemosphere & 52 & $2 \%$ \\
Environmental Pollution & & \\
International Journal Of Environmental Research And Public & 49 & $3 \%$ \\
Health & 45 & $1 \%$ \\
Huanjing Kexue Environmental Science & 42 & $6 \%$ \\
Journal Of Hazardous Materials & & \\
Desalination And Water Treatment & 41 & $3 \%$ \\
\hline
\end{tabular}


In 2019, 34\% of those articles were co-authored by researchers from Chinese institutions, $6 \%$ from India and 5\% from USA (Figure 5), reflecting in part the emergence of intense research activity on widespread environmental issues in the region and as already outlined by Pourret and Hursthouse[20], emerging reports in English language journals, perhaps has enhanced the growth of the term, a result of perpetuating the approach to an established and long-standing practice.

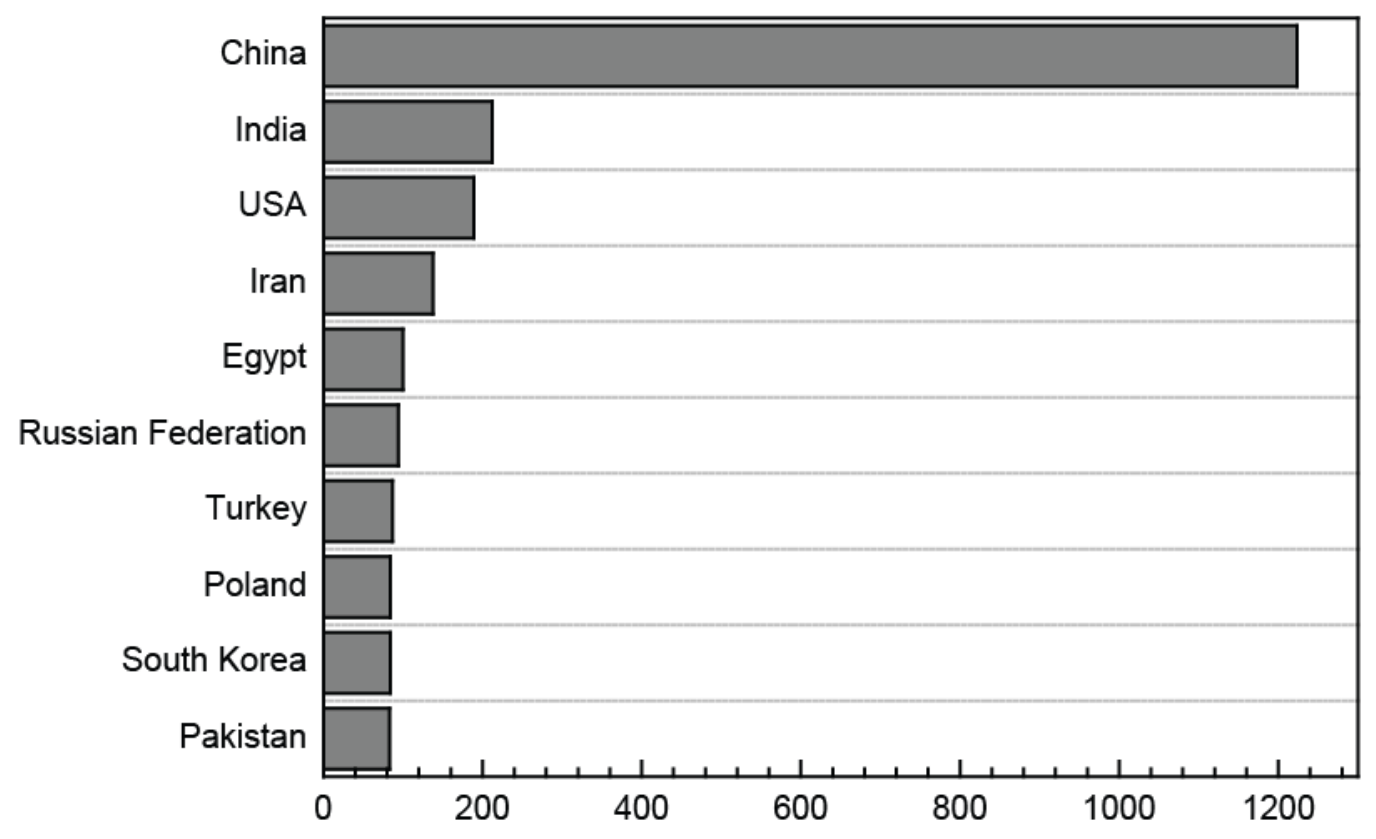

Figure 5 Article distribution by country (top 10) of articles published in 2019 having the term heavy metal ${ }^{*}$ in the title (country based on authors affiliation, several countries may count for the same article).

Thanks to social media, the debate is also relayed to a larger audience (e.g. sketchnote on twitter, Figure 6). 


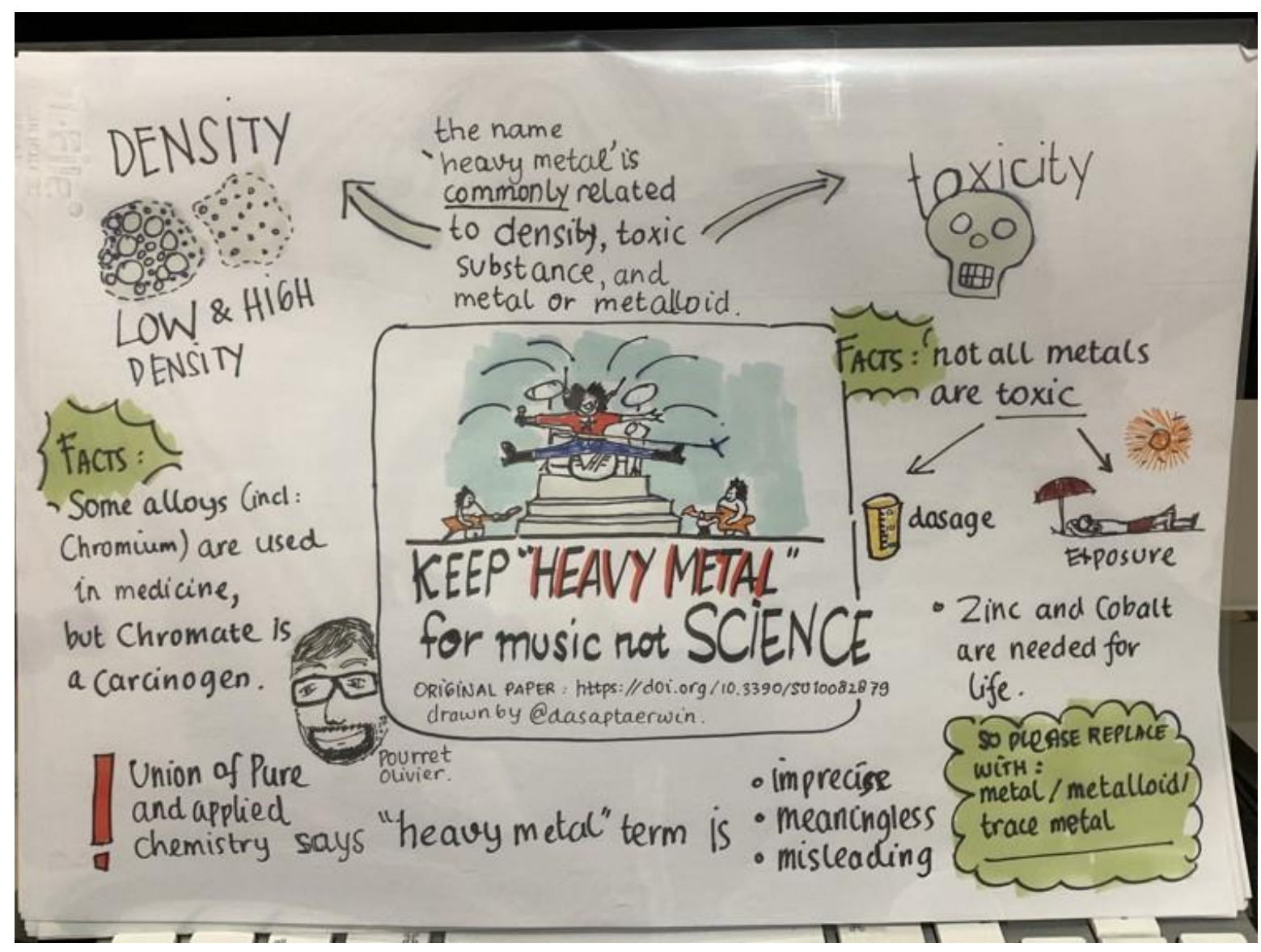

Figure 6 Sketchnote illustrating the misused term "heavy metal" (artwork from Dr.

Dasapta Erwin Irawan)[25].

\section{Discussion}

As already proposed by Hübner et al.[7], solutions exist to deal with the long-standing problem of the imprecise usage of the term "heavy metals" in the scientific literature. Some authors propose:

(i) Formulating one single scientific definition. This would be an ideal approach, but unlikely to be adopted. A general agreement about a single atomic mass, atomic number, density or another similar criterion will be difficult to achieve. Indeed, Ali and Khan [14] try to but half of the periodic table is considered by this definition (Figure 1).

(ii) Calling the ten elements most commonly considered as "heavy metals", $\mathrm{Cr}, \mathrm{Co}, \mathrm{Ni}, \mathrm{Cu}$, $\mathrm{Zn}, \mathrm{As}, \mathrm{Cd}, \mathrm{Sn}, \mathrm{Hg}, \mathrm{Pb}$ as "heavy metals", all other elements not. It is basic and to a certain degree arbitrary, but at least uniform and based on a mutual understanding[7], though metalloids are still included. 
We propose:

(i) Replacement of the term "heavy metals" with a reasonable and scientifically defendable terms like "potentially toxic element", "trace metal element", "metal", "metalloid" in environmental studies[20].

(ii) Avoiding the problem by not using this umbrella term and referring simply to metals or elements. This is a reasonable approach and is probably the only approach that ultimately might successfully suppress the term "heavy metals"[18].

\section{Conclusions}

To be consistent, researchers should only use well-accepted definitions. In the case of "heavy metal", this term should be replaced by "metal", "metalloid" according to the case, or by "trace metal" or "potentially toxic element" when this can be considered . The best way to describe the studied elements is clearly to name them or consider them as a group of elements (metals or metalloids).

Funding: This research received no external funding.

Conflicts of Interest: The author declares no conflict of interest.

\section{References}

1. Ghibaudi, E., Levi's Periodic System vs. Mendeleev's Periodic System: two engaged views of chemistry between science and literature. Pure and Applied Chemistry 2019, 91 (12), 1941-1947. doi:10.1515/pac-2019-0604.

2. Wagman, J. B.; Zimmerman, C.; Sorric, C., "Which Feels Heavier-A Pound of Lead or a Pound of Feathers?” A Potential Perceptual Basis of a Cognitive Riddle. Perception 2007, 36 (11), 1709-1711. doi:10.1068/p5854.

3. Nieboer, E.; Richardson, D. H. S., The replacement of the nondescript term 'heavy metals' by a biologically and chemically significant classification of metal ions. 
Environmental Pollution. Series B, Chemical and Physical 1980, 1 (1), 3-26. doi:10.1016/0143-148X(80)90017-8.

4. Duffus, J. H., "Heavy metals" a meaningless term? (IUPAC Technical Report). Pure and Applied Chemistry 2002, 74, 793-807. doi:10.1351/pac200274050793.

5. Hodson, M. E., Heavy metals - Geochemical bogey men? Environmental Pollution 2004, 129 (3), 341-343. doi:10.1016/j.envpol.2003.11.003.

6. Chapman, P. M., Heavy metal - Music, not science. Environmental Science and Technology 2007, 41 (12), 6C.

7. Hübner, R.; Astin, K. B.; Herbert, R. J. H., 'Heavy metal'-time to move on from semantics to pragmatics? Journal of Environmental Monitoring 2010, 12 (8), 1511-1514. doi:10.1039/C0EM00056F.

8. Madrid, L., "Heavy metals": Reminding a long-standing and sometimes forgotten controversy. Geoderma 2010, 155 (1), 128-129. doi:10.1016/j.geoderma.2009.11.031.

9. Nikinmaa, M.; Schlenk, D., Uses of phrases. Aquatic Toxicology 2010, 97 (1), 1-2. doi:10.1016/j.aquatox.2010.02.015.

10. Bhat, U. N.; Khan, A. B., Heavy Metals: An Ambiguous Category of Inorganic Contaminants, Nutrients and Toxins. Research Journal of Environmental Sciences 2011, 5, 682-690. doi:10.3923/rjes.2011.682.690.

11. Chapman, P. M., "Heavy metal" - Cacophony, not symphony. Integrated Environmental Assessment and Management 2012, 8 (2), 216. doi:10.1002/ieam.1289.

12. Batley, G. E., "Heavy metal"- a useful term. Integrated Environmental Assessment and Management 2012, 8 (2), 215-215. doi:10.1002/ieam.1290.

13. Appenroth, K.-J., What are "heavy metals" in Plant Sciences? Acta Physiologiae Plantarum 2010, 32 (4), 615-619. doi:10.1007/s11738-009-0455-4.

14. Ali, H.; Khan, E., What are heavy metals? Long-standing controversy over the scientific use of the term 'heavy metals' - proposal of a comprehensive definition. Toxicological \& Environmental Chemistry 2018, $100 \quad$ (1), 6-19. doi:10.1080/02772248.2017.1413652.

15. Alloway, B. J., Heavy Metals in Soils - Trace Metals and Metalloids in Soils and their Bioavailability - Third Edition. Springer: 2013; p 614.

16. Gupta, A., Heavy Metal and Metalloid Contamination of Surface and Underground Water. CRC Press: 2020; p 278.

17. Lambers, H.; Oliveira, R. S., Plant Physiological Ecology. Springer: 2019; p 736.

18. Pourret, O.; Bollinger, J. C., "Heavy metal" - What to do now: To use or not to use? Science of the Total Environment 2018, 610-611, 419-420. doi:10.1016/j.scitotenv.2017.08.043.

19. Pourret, O., On the necessity of banning the term "heavy metal" from the scientific literature. Sustainability (Switzerland) 2018, 10 (8). doi:10.3390/su10082879.

20. Pourret, O.; Hursthouse, A., It's Time to Replace the Term "Heavy Metals" with "Potentially Toxic Elements" When Reporting Environmental Research. International Journal of Environmental Research and Public Health 2019, 16 (22). doi:10.3390/ijerph16224446.

21. Pourret, O.; Bollinger, J.-C.; van Hullebusch, E. D., On the difficulties of being rigorous in environmental geochemistry studies: some recommendations for designing an 
impactful paper. Environmental Science and Pollution Research 2020, 27 (2), 1267-1275. doi:10.1007/s11356-019-06835-y.

22. Belkhiri, L.; Mouni, L.; Sheikhy Narany, T.; Tiri, A., Evaluation of potential health risk of heavy metals in groundwater using the integration of indicator kriging and multivariate statistical methods. Groundwater for Sustainable Development 2017, 4, 12-22. doi:10.1016/j.gsd.2016.10.003.

23. Antoniadis, V.; Shaheen, S. M.; Levizou, E.; Shahid, M.; Niazi, N. K.; Vithanage, M.; Ok, Y. S.; Bolan, N.; Rinklebe, J., A critical prospective analysis of the potential toxicity of trace element regulation limits in soils worldwide: Are they protective concerning health risk assessment? - A review. Environment International 2019, 127, 819-847. doi:10.1016/j.envint.2019.03.039.

24. Chivers, P. T., Chapter 14 Cobalt and Nickel. In Binding, Transport and Storage of Metal Ions in Biological Cells, The Royal Society of Chemistry: 2014; pp 381-428.

25. Irawan, D. E., Keep heavy metal for music not science. Zenodo 2020. doi:10.5281/zenodo.4134463. 